\title{
Antioxidant content of Greek herb extracts and evaluation of antioxidant capacity in pork samples
}

\author{
D. J. Triantafillou ${ }^{1}$, S. Chatziantoniou ${ }^{2}$, A. Bathrakis ${ }^{2}$ and C. Hatzigrigorakis ${ }^{2}$ \\ ${ }^{1}$ Department of Nutrition and Dietetics and ${ }^{2}$ Department of Food Technology, Alexander Technological Educational \\ Institute (ATEI) of Thessaloniki, School of Food Technology and Nutrition, Thessaloniki, Greece
}

The addition of natural antioxidants to food products has been shown to prolong shelf-life, as well as the stability of organoleptic characteristics and nutritional quality ${ }^{(1)}$. To explore the antioxidant potential of herbs, the antioxidant content of extracts and decoctions from ten varieties of uncultivated herbs, collected from the Ritini area, Pieria county, Greece, was determined by the ferric-reducing antioxidant power method ${ }^{(2)}$. Extracts were prepared by adding herbs to water $(5 \mathrm{~g} / \mathrm{L})$, heating until boiling point, boiling for $10 \mathrm{~min}$ and filtering, while decoctions were prepared by adding herbs to boiling water, boiling for $10 \mathrm{~min}$ and filtering. Three-way ANOVA was used to evaluate the data.

Figure 1 shows the effects of the studied factors affecting the antioxidant content of herb species.

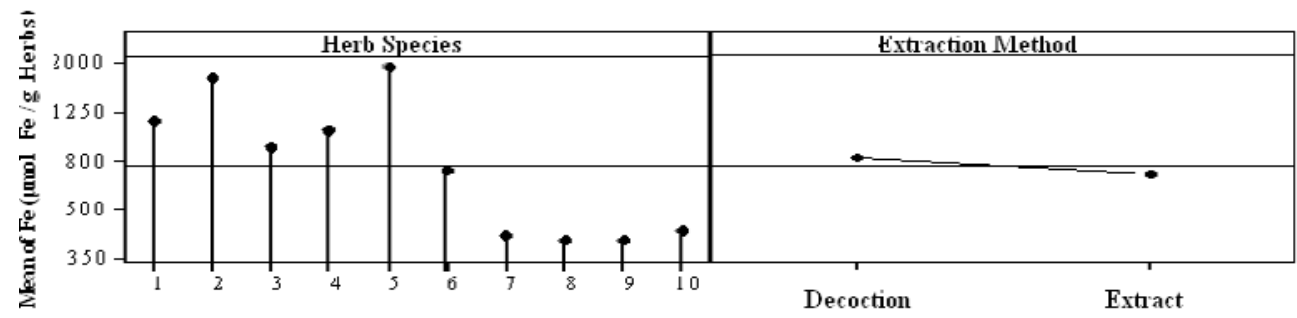

Fig. 1. Effects of species and extraction method on antioxidant content ( $\mu$ mol Fe/g herbs $)(P<0.01)$. (Herb species: 1) Mint; 2) Melissa herb; 3$)$ Thyme; 4) Thyme uncultivated; 5) Oregano; 6) Sage 1; 7) Sage 2; 8) Yellow achillea; 9) White achillea 1;10) White achillea 2).

The antioxidant content of the herbs was found to be highly dependent on the species and the geographical origin of the herb samples. The extract and decoction with the highest antioxidant activity $(\mu \mathrm{mol} \mathrm{Fe} / \mathrm{g})$ were those derived from samples of oregano (Oregano vulgare) from the Ritini area (1910 and 2430 respectively), followed by samples of melissa herb (Melissa officinalis) from the Arni area (1900 and $1505 \mu$ mol Fe/g respectively) and samples of mint (Mentha spp.; 1155 and 1816 respectively), thyme (Thymus spp.; 840 and 1180 respectively), sage (Salvia sclarea; 518 and 857 respectively), white achillea (Achillea milletolium, Compositae; 640 and 490 respectively) and yellow achillea (Achillea milletolium, Coarctata; 490 and 668 respectively).

Furthermore, analysis of the data showed that herb decoctions had higher antioxidant activities than herb extracts, while a gradual decrease in antioxidant activity was observed for all herb samples during storage for 6 weeks at $-18^{\circ} \mathrm{C}$.

To evaluate the antioxidant capacity of the most active extract, freeze-dried oregano extracts were added to pork samples and inhibition of meat fat oxidation was measured by estimating the malonaldehyde content, which as a secondary product of fat oxidation is used as an index of oxidation (thiobarbituric acid test ${ }^{(3)}$ ).

Analysis of the data by two-way ANOVA (Fig. 2) showed that the addition of oregano extracts to minced pork samples strongly inhibited fat oxidation. The addition of oregano extracts to pork samples maintained at $90^{\circ} \mathrm{C}$ for $2,4,6$ and $24 \mathrm{~h}$ significantly retarded fat oxidation by $27,32,37$ and $30 \%$ respectively.

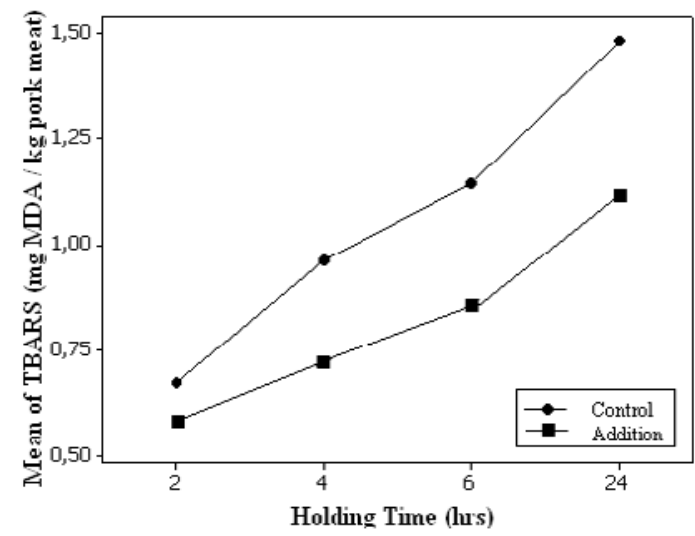

Fig. 2. TBARS of pork samples, as affected by holding time at $90^{\circ} \mathrm{C}$ and addition of oregano extract $(P<0.01)($ Control: Pork samples; Addition: Pork samples to which oregano extract was added).

Conclusively, all herbs studied can be cultivated and utilised as natural sources of antioxidants. Natural antioxidants can be effectively used for the formulation of meat products with prolonged shelf-life, as was shown by the results on inhibition of meat lipid oxidation by oregano extract.

1. Botsoglou NA, Govaris A, Botsoglou EN, Grigoropoulou SH \& Papageorgiou G (2003) J Agric Food Chem 51, $2930-2936$.

2. Benzie IFF \& Strain JJ (1996) Anal. Biochem 239, 70-76.

3. Mansour EH \& Khalil AH (2000) Food Chem 69, 135-141. 